be transmitted to man from wild animals and birds. It should be realized, however, that many of these diseases are repeated in each of the lists, so that the total number of diseases is correspondirgly reduced. A final list, 9 pages long, gives a useful summary of all the diseases, with their ætiological agents, their common animal hosts and the usual methods by which man may be infected.

One purpose of the book is to provide a common meeting ground for the physician, health official, veterinarian and research worker, and in this it should succeed. It will help, one hopes, to foster the movement, now gathering force, towards close co-operation between the medical man, the veterinarian and the biologist in the fascinating field of comparative medicine and surgery. Some readers may find that the space given to some of the diseases considered might havo been extended and that given to others shortened, but opinions about this will vary accord. ing to the special interests of the reader and the importance of certain diseases in particular parts of the world. The scope of the book is, it should be remembered, worldwide, and the 32 contributors have been given considerable freedom in their treatment of the subjects allotted to them.

The book is well printed on thick, glossy paper and this makes it rather a heavy book to handle; but no doubt this paper helps the reproduction of the illustrations, most of which are photographs of lesions in man and other animals. Many of these will be valuable to practising medical men and veterinarians. The general production of the book maintains the high standard that we have learnt to expect from its publisher.

G. LAPAGE

\section{ABSORPTION OF LIPIDS FROM THE INTESTINE}

\section{Biochemical Problems of Lipids}

Edited by A. C. Frazer. (B.B.A. Library, Volume 1.) Pp. ix +474 . (Amsterdam, London and New York: Elsevier Publishing Company, 1963.) 130s.

$\mathrm{T}$

HIS volume contains the fifty-eight papers read at the seventh international conference on "Biochemical Problems of Lipids", held in Birmingham during June 24-27, 1962. The main theme was the mechanism of fat absorption from the intestine. Papers concerned with this subject were classified thus: (1) intraluminal aspects of fat absorption; (2) structural aspects of the intestinal cell and absorption studies; (3) enzymatic aspects of intestinal lipid metabolism; (4) ehylomicrons and lipoproteins.

In Section 1 there is frequent reference to the use of thin-layer chromatography for detecting the products of enzymatic hydrolysis of triglycerides and identifying individual bile acids. The role of bile in the solubilization of synthetic hydrocarbons and dyestuffs has also been investigated, as have the effects of diversion of the bile on the recovery of lipids in the thoracic-duct lymph. In addition there are papers on the amount and composition of the fæcal fats of several species, which have been examined with particular reference to the influence of the intestinal bacteria.

There are important papers in Section 2 dealing with the fine structure of intestinal epithelial cells and particularly with the brush border, as observed under the electron microscope. Results obtained by different groups have been presented in support of possible mechanisms of lipid absorption from the intestine. It appears that at present there is still a great deal of uncertainty regarding the naturo of this process. Opinion seems to be rather eventy divided in favour of absorption of lipid droplets by pinocytosis on one hand, and of a highly dispersed molecular or micellar species on the other.
In Section 3, the main line of research concerns the re-synthesis of triglyceride in the intestinal mucosal cells. It seems to be generally accepted that the most important pathway in this tissue involves the condensation of monoglyceride with two molecules of longchain acyl-coenzyme A. Thus intestinal mucosa differs from other tissues in which triglyceride synthesis begins with the acylation of $\mathrm{L}$ - $\alpha$-glycerophosphate.

One of the papers in Section 4 deals with the composition of rat thoracic-duct lymph as a function of the nature of the dietary triglyceride. Lipids containing fatty acid radicals of short and intermediate chain length $\left(\mathrm{C}_{4}-\mathrm{C}_{10}\right)$ are not found in the lymph draining the intestine, following oral administration of the triglycerides of these fatty acids; on the other hand, the long-chain component fatty acids $\left(\mathrm{C}_{12}-\mathrm{C}_{18}\right)$ do appear in the lymph under comparable experimental conditions.

Only about two-thirds of the papers presented deal with the main absorption theme. The rest are divided into two additional sections: (5) mitochondrial and other aspects of lipid metabolism and (6) wider aspects of lipid metabolism. Some of the most interesting papers in the whole volume are to be found in these two sections. Thus in Section 5 there is an excellent account of the role of lipids in mitochondrial electron transfer and oxidative phosphorylation; also a very careful investigation of the cause of fatty livers in rats following injection of either ethionine or puromycin.

In Section 6 there are important investigations on the lipids of the erythrocyte membrane. The solubilization of these lipids has been examined following treatment with hypotonic saline and various hæmolytic agents. The lipid composition of the erythrocyte membranes of different species has been determined and incorporation of lysolecithin and linoleic acid into the lecithin component has been observed. Other papers of interest deal with the synthesis of unsaturated fatty acids by yeast, the effect of essential fatty acids in the diet on the lipid composition of rat heart and the metabolism of linoleic acid in rat liver.

Each paper is followed by a discussion of variable length, but only about half the papers contain a summary. A subject index has been provided, which seems to have been compiled exclusively from words appearing in the titles; similar topics are thus not necessarily brought together.

This volume does not attempt to give a connected account of the absorption of lipids from the intestine. Instead, it presents a series of investigations designed to solve some outstanding problems. For this reason, the book will probably appeal to lipid workers, whatever their specialized interest, but it is doubtful to what extent it will be read by others.

\section{HIGH-PRESSURE PHYSICS AND CHEMISTRY}

High Pressure Physics and Chemistry

Edited by R. S. Bradley. Vol. 1: Pp. xi $+444.100 s$. Vol. 2: Pp. xii +361. 80s. (London: Academic Press, Inc. (London), Ltd.; New York: Academic Press, Inc., 1963.)

HE progress of the physical sciences may be likened
to an incoming tide, the advancing waters presenting
an uneven front but the general level rising at a fairly
uniform rate; new techniques and discoveries in a particu-
lar sector invariably generate points of growth in neigh-
bouring sectors and thus contribute to the overall advance.
The history of high-pressure technology affords an excel-
lent example of this process. Improvements in experi-
mental methods, the specific demands of industry and
the need to confirm the predictions of theory have, in 